\title{
PIBID: O ENSINO DOS ESTRANGEIRISMOS POR MEIO DA APRENDIZAGEM BASEADA EM PROBLEMAS
}

\author{
PIBID: LA ENSEÑANZA DE LOS EXTRANJERISMOS POR MEDIO DEL \\ APRENDIZAJE BASADO EN PROBLEMAS
}

\author{
PIBID: THE FOREIGNISM TEACHING THROUGH THE PROBLEM BASED \\ LEARNING
}

\author{
Alana Gabriele da SILVA ${ }^{1}$ \\ Carlos Vinícius OLÍMPIO² \\ Lívia Carolina Baenas BARIZON ${ }^{3}$
}

RESUMO: O ensino atual tornou-se um desafio no cotidiano dos professores mais velhos, bem como os jovens licenciados, pois a moderna sociedade do conhecimento necessita que os mesmos repensem suas práticas pedagógicas diariamente, além disso, é esperado que os educadores tornem-se articuladores, mediadores e reflexivos implicando proporcionar aos alunos um aprendizado autônomo e inovador modificando o processo de ensino superando a transmissão de conhecimento conservadora. O Pibid é um elo entre as secretarias estaduais e municipais de educação com as universidades brasileiras, que visa proporcionar a melhoria da educação pública, além de, fazer uma reforma positiva na formação dos novos licenciados. Portanto, busca-se nesse relato de experiência apresentar uma sequência didática sobre a utilização dos estrangeirismos, aplicada no subprojeto de Letras Português, a qual consistiu no uso da metodologia ativa da aprendizagem baseada em problemas, que modificou o ensino tradicional dando espaço para a produção do conhecimento autônomo e com significado.

PALAVRAS-CHAVE: PIBID. Estrangeirismos. Aprendizagem baseada em problemas.

RESUMEN: La enseñanza atual se volvió un desafio en el cotidiano de los profesores más viejos, bien como los jóvenes licenciados, porque la moderna sociedad del conocimiento necesita que los mismos, piensen otra vez sus practicas pedagógicas diariamente, además, se espera que los educadores conviertanse en articuladores, mediadores y reflexivos haciendo con que proporcionen a los alumnos un aprendizaje autónomo e innovador, cambiando el proceso de enseñanzas, superando la transmisión del conocimiento conservadora. El Pibid es una relación entre las secretarias de los estados y municípios de educación con las universidades brasileñas, que tienen como objectivo proporcionar una mejora en la educación pública, además de hacer un cambio positivo en la formación de los nuevos licenciados. Así, en este artigo, se busca presentar una secuencia didáctica acerca de la

${ }^{1}$ Universidade Sagrado Coração (USC), Bauru - SP - Brasil. Graduada em Letras Licenciatura. ORCID: <https://orcid.org/0000-0002-6570-0687>. E-mail: alanagdasilva@hotmail.com

${ }^{2}$ Universidade Sagrado Coração (USC), Bauru - SP - Brasil. Graduando do curso de Letras Licenciatura. ORCID: <https://orcid.org/0000-0001-9602-504X>. E-mail: carlos.volimpio@ hotmail.com

${ }^{3}$ Universidade Sagrado Coração (USC), Bauru - SP - Brasil. Docente. Mestra em Letras no Programa: Filologia e Língua Portugues pela Universidade de São Paulo (USP). ORCID: 〈https://orcid.org/0000-0002-7659-7195>. E-mail: livia.barizon@gmail.com 
utilización de los extranjerismos, aplicada en el subproyecto de Letras Portugués, la que consistió en el uso de la metodologia activa del aprendizaje basado en problemas, que modifico la enseñanza tradicional, cediendo un espacio para la producción del conocimiento autónomo y con un significado.

PALABRAS CLAVE:PIBID. Extranjerismos. Aprendizaje basado en problemas.

ABSTRACT: The current teaching has become a challenge in the daily lives of older teachers as well as for young graduates because the modern society knowledge needs them to rethink their pedagogical practices day to day. Besides that it's expected that educators become articulators, mediators and reflectors providing to students an autonomous and innovative learning, modifying the teaching process and overcoming the conservative knowledge's transmission.

PIBID is a link between state and municipal education secretariat and the Brazilians universities which aims to improve public education as well as make a positive reform in the new teachers' training. Therefore, it's seek in this article to present a didactic sequence on the use of foreignisms applied in the subproject of Portuguese which constituted in the use of active learning methodology based on problems that modified traditional teaching, enabling the production of autonomous and significant knowledge.

KEYWORDS: PIBID. Foreignism. The problem based learning.

\section{Introdução}

A nova geração do conhecimento tem desafiado os professores da educação básica a repensar suas práticas docentes, como resultado, o professor torna-se versátil, pois segundo Behrnes (2006) além de profissional competente, precisa tornar-se um cidadão autônomo e criativo que saiba solucionar e manter constantes iniciativas para questionar e transformar a sociedade.

Portanto, foi criada uma nova perspectiva sobre a educação que visa proporcionar autonomia aos alunos, por meio da visão crítica e reflexiva, na qual os professores devem aplicar práticas contemporâneas (metodologias, abordagens e estratégias) incitando a reflexão dos conteúdos. Nesse cenário, muito tem sido desenvolvido e estudado sobre as metodologias ativas, que permitem o desenvolvimento das habilidades cognoscitivas por meio do eixo epistemológico e prático ativo da aprendizagem aproximando o estudante da realidade, e repensando a concepção das formas tradicionais de aprendizagem centradas na transmissão passiva de conhecimentos. Morán (2015, p. 18) afirma: 
As metodologias ativas, nesse contexto, podem favorecer a problematização e contextualização dos conceitos, uma vez que parte de um problema para gerar uma situação de aprendizagem. Esse tipo de metodologia é ponto de partida para alcançarmos processos mais avançados de reflexão, de integração cognitiva, de generalização, de reelaboração de novas práticas.

Porém, isso não significa abandonar as aulas expositivas dialogadas nem cumprir todo cronograma escolar com metodologias ativas, mas é preciso que seja feito a personalização do ensino. Além disso, as metodologias ativas buscam despertar a curiosidade dos alunos, promovendo a aprendizagem significativa. Berbel (2011, p. 28) conclue:

A implementação dessas metodologias pode vir a favorecer uma motivação autônoma quando incluir o fortalecimento da percepção do aluno de ser origem da própria ação, ao serem apresentadas oportunidades de problematização de situações envolvidas na programação escolar, de escolha de aspectos dos conteúdos de estudo, de caminhos possíveis para o desenvolvimento de respostas ou soluções para problemas que se apresentam alternativas criativas para a conclusão do estudo ou da pesquisa, entre outras possibilidades.

Então, surge a metodologia ativa da Aprendizagem Baseada em Problemas (ABP) que segundo Souza e Dourado (2015, p. 184) é uma estratégia de método para a aprendizagem, centrada no aluno e por meio da investigação, tendo em vista à produção de conhecimento individual e grupal, de forma cooperativa, e que utiliza técnicas de análise crítica, para a compreensão e resolução de problemas de forma significativa e em interação contínua com o professor tutor. Nela, o processo de aprendizagem tem início quando o professor elabora uma situação de aprendizagem sistematizando um problema a partir do conteúdo específico, já estabelecido pelo currículo.

Em vista disto, os licenciandos do subprojeto de Letras Português criaram uma situação de aprendizagem baseada no currículo dos alunos do $8^{\circ}$ ano do ensino fundamental, o qual é composto pelo conteúdo de anúncios publicitários, que já haviam sido estudados nas aulas de Língua Portuguesa, visando à metodologia ativa ABP. Além de, traçar um elo com a temática dos estrangeirismos, que estava sendo desenvolvida e estudada nas aulas do PIBID de Português.

Enfim, é importante ressaltar que o PIBID (Programa Institucional de Bolsa de Iniciação à Docência) foi criado visando ao melhoramento da educação dos licenciandos das universidades públicas e privadas, além de oferecer uma assistência e criar um vínculo entre secretárias municipais e estaduais de educação com a universidade. Sob a orientação de professores universitários e também professores experientes da educação básica, os bolsistas 
realizam propostas de intervenção docente nas instituições de ensino tanto fundamental quanto médio.

Souza e Dourado (2015, p. 185) expressam que a estrutura da ABP foi concebida justamente para que o aluno desenvolva as habilidades e capacidades para proceder à investigação de forma metódica e sistemática; para aprender a trabalha em grupo cooperativo e alcançar os resultados da pesquisa, de forma satisfatória complementando sua aprendizagem individual.

Dessa maneira, os alunos já haviam estudado o conteúdo de anúncios publicitários, com a professora titular de Língua Portuguesa. Então no PIBID, primeiramente foi feita uma aula expositiva sobre o conteúdo estrangeirismos, presente no currículo de Língua Portuguesa. Em seguida, houve um levantamento com a participação dos estudantes acerca das palavras estrangeiras mais utilizadas no contexto social dos mesmos, elas poderiam ser incorporadas ao léxico ou não. Para tanto, as informações foram colocadas na lousa, conforme os professores faziam reflexões sobre o cotidiano dos alunos e a utilização de produtos (aplicativos eletrônicos, alimentícios, serviços, etc.), que continham termos estrangeiros.

A sequência didática seguiu com a leitura compartilhada do texto "Leve dicionário na hora de ir às compras", e uma investigação no conceito prévio dos alunos, após ocorreu a proposta de redação, na qual os alunos seriam responsáveis por escrever uma narrativa utilizando os estrangeirismos.

Souza e Dourado (2015, p. 191) afirmam que o cenário deve ser escolhido a partir de um contexto real, que faz parte da vida dos alunos, para que haja uma identificação imediata do problema motivando-os a continuar o desenvolvimento da atividade investigativa. Portanto, na aula seguinte houve a leitura da notícia "Aprovado projeto que proíbe estrangeirismo" retirada da Folha de São Paulo de Brasília e escrita por Luciana Constantino no ano de 2001, e foi feito um debate sobre a mesma entre os alunos com o auxílio dos professores. Também foram respondidos alguns exercícios sobre essa notícia e apresentado o problema que rege a metodologia ativa da atividade.

O problema consistia que o projeto de lei foi realmente aprovado e os alunos, em grupos, produziriam um anúncio publicitário sem utilizar as palavras estrangeiras: shopping, milk-shake, capuccino, pet-shop e sunday, mas criassem palavras portuguesas que substituíssem as mesmas, e que mantivessem o significado, conceito essencial, das palavras estrangeiras mencionadas.

Como já mencionado na metodologia, os alunos vivenciaram processos que geraram sua autonomia, por meio da apresentação do problema, eles buscaram aprofundar-se no 
assunto para encontrar as soluções. Souza e Dourado (2015, p. 198) afirmam que os alunos dominam o conhecimento e apresentam seus resultados, com mais segurança, visto serem estes frutos de um processo de investigação e reflexão conduzido por eles mesmos e não, simplesmente, se limitam a apresentar respostas prontas a questões dadas pelo professor; os alunos exercitam suas habilidades de formulação de questões-problemas e análise crítica do cenário para a compreensão e resolução dos problemas. Dessa maneira, durante a confecção dos cartazes, houve pesquisas e compartilhamento das ideias, buscando melhores adaptações para a palavra estrangeira.

Souza e Dourado (2015, p. 198) também afirmam que os alunos desenvolvem a capacidade de inter-relação e cooperação no trabalho em grupo, pois buscam as informações e avaliam sua importância para a resolução dos problemas e aprendem com autonomia, por fim, desenvolvem a capacidade de autoavaliação e avaliação do desempenho dos integrantes do grupo. Após a confecção dos anúncios publicitários e as suas respectivas apresentações, os alunos discutiram a performance do grupo, e de que maneira isso contribuiu para sua aprendizagem individual.

As palavras milk-shake, shopping, capuccino, pet-shop e sunday se transformaram respectivamente em batidão de leite, misturadão de café, lojão do cachorrão e centro de lojas. Os alunos mantiveram o significado dos termos estrangeiros, pois as produções dos seus anúncios foram baseadas no conceito destes. Além disso, os alunos seguiram, mesmo que inconscientemente, um enfoque do fenômeno léxico-semântico de base onomasiológico, pois com base no conceito da palavra, em sua definição (significado), propuseram novas designações (significante).

$\mathrm{Na}$ estruturação do Léxico, a Onomasiologia representa a face das designações, ao passo que a Semasiologia representa a face das significações. Em outras palavras, um campo onomasiológico compreende todos os significantes (designações, nomes) de um dado significado. (BALDINGER, 1966 apud BIDERMAN, 1978, p. 155)

\section{Considerações finais}

De acordo com Berbel (1998), o trabalho com problemas em sala de aula enfatiza o aprender a aprender. Além disso, o mesmo autor ressalta que a natureza dos problemas e a forma por meio da qual são construídos e propostos tem como objetivo fazer com que o aluno saiba reconhecer contexto conceitual a partir dos conteúdos necessários para a resolução do 
problema e que, no entanto, são desconhecidos pelos alunos. Assim, os resultados positivos foram corroborando para tal tese, pois os alunos vivenciaram processos que geram autonomia para aprender, por meio da criatividade e inovação. Bem como, segundo Souza e Dourado (2015, p.187) como os problemas são apresentados num contexto real, favorecem a transferência dos conhecimentos e habilidade aprendidos em sala de aula para o mundo do trabalho, ou seja, a produção de conhecimento passou a ter significado na vida dos estudantes, visto que estabelece relações com suas vidas cotidianas. Também é possível afirmar que o processo de aprender a aprender implicou em formular questões, investigar, localizar fontes de informação, a fim de saber escolher o que é relevante para encontrar possíveis soluções para o problema proposto.

\section{REFERÊNCIAS}

ALVES, I. M. Neologismo: criação lexical. São Paulo: Ática, 2002.

BEHRENS, M. A. O paradigma da complexidade. Metodologia de projetos, contratos didáticos e portfólios. Petrópolis: Vozes, 2006.

BERBEL, N. A. N. As metodologias ativas e a promoção da autonomia de estudantes.

Semina: Ciências Sociais e Humanas, v. 32, n. 1, p. 25-40, 2011.

BIDERMAN, M. T. C. Teoria linguística (linguística quantitativa e computacional). Rio de Janeiro: Livros Técnicos e Científicos, 1978.

FARACO, C. A. (org.) Estrangeirismos: guerras em torno da língua. São Paulo: Parábola, 2001.

MORÁN, J. M. Mudando a educação com metodologias ativas. Coleção Mídias Contemporâneas-Convergências Midiáticas, Educação e Cidadania: aproximações jovens, v. 2, 2015.

SOUZA, S. C.; DOURADO, L. Aprendizagem baseada em problemas (ABP): um método de aprendizagem inovador para o ensino educativo. HOLOS, v. 5, p. 182-200, 2015.

\section{Como referenciar este artigo}

SILVA, Alana Gabriele da.; OLÍMPIO, Carlos Vinícius.; BARIZON, Lívia Carolina Baenas. PIBID: O Ensino dos estrangeirismos por meio da Aprendizagem Baseada em Problemas. Rev. EntreLínguas, Araraquara, v. 4, n. 2, p. 302-307, jul./dez. 2018. E-ISSN: 2447-3529. DOI: 10.29051/rel.unesp.v4.n2.2018.11675 